Kai A. Konrad

Marcel Thum

\title{
Climate Policy Negotiations with Incomplete Information
}

Max Planck Institute for Tax Law and Public Finance

Working Paper 2011 - 19

December 2011

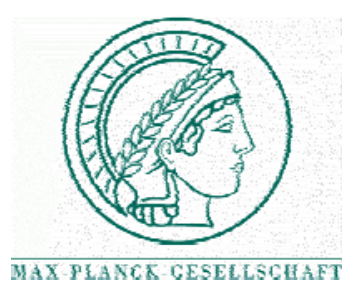

Max Planck Institute for

Tax Law and Public Finance

Department of Business and Tax Law

Department of Public Economics

http:/ / www.tax.mpg.de 
Working papers of the Max Planck Institute for Tax Law and Public Finance Research Paper Series serve to disseminate the research results of work in progress prior to publication to encourage the exchange of ideas and academic debate. Inclusion of a paper in the Research Paper Series does not constitute publication and should not limit publication in any other venue. The working papers published by the Max Planck Institute for Tax Law and Public Finance represent the views of the respective author(s) and not of the Institute as a whole. Copyright remains with the author(s).

Max Planck Institute for Tax Law and Public Finance

Marstallplatz 1

D-80539 Munich

Tel: $\quad+498924246-0$

Fax: $\quad+498924246-501$

E-mail: ssrn@tax.mpg.de

http://www.tax.mpg.de 


\title{
Climate policy negotiations with incomplete information*
}

\author{
Kai A. Konrad ${ }^{\dagger}$ and Marcel Thum ${ }^{\ddagger}$
}

April 12, 2012

\begin{abstract}
We analyze bargaining over international climate agreements in a setting with incomplete information about abatement costs. Incomplete information is known as one of the key reasons why negotiations may fail more generally, and why efficiency gains cannot be exploited. We ask whether unilateral commitment to high abatement reduces or increases the likelihood for an efficient negotiation outcome. We find that such commitment behavior reduces the gains from global cooperation, and that, in turn, this reduces the probability of reaching efficient international environmental agreements.

JEL classification code: Q54, Q58, F53, H41

Keywords: mitigation, international climate agreements, bargaining, unilateral advances

\footnotetext{
${ }^{*}$ We thank Achim Wambach for helpful discussion. The usual caveat applies. An earlier version of the paper was entitled "Unilateral action and negotiations about climate change".

${ }^{\dagger}$ Corresponding author. Max Planck Institute for Tax Law and Public Finance, Marstallplatz 1, D-80539 Munich, Germany, phone: +49 89 2424-65250, fax: +49 89 2424-65299 and Social Science Research Center Berlin, Germany. E-mail: kai.konrad@tax.mpg.de.

${ }^{\ddagger}$ Faculty of Business and Economics, Technical University Dresden, D-01062 Dresden, Germany, phone: + 49351 463-33867, fax: + 49351 463-37052 and ifo-Dresden, Germany. E-mail: marcel.thum@tu-dresden.de.
} 


\section{Introduction}

Unilateral pre-commitment to high emissions reductions is a much debated issue in climate policy. In a seminal paper, Hoel (1991) shows that the additional abatement chosen by a leader country, which pre-commits on such unilateral advances, is typically crowded out by other countries in the noncooperative equilibrium and relocates the cost of abatement from the other countries to the country that makes such a commitment. This crowding-out effect has proven to be very strong and stable in non-cooperative settings. It has also been shown that countervailing forces from information spillovers and through technological externalities may exist. ${ }^{1}$

Of course, negotiations at climate summits do not aim at the noncooperative outcome. They aim at overcoming the inefficiencies of noncooperative equilibrium and at reaching an efficient outcome. This points to the question of whether high unilateral abatement commitments, while potentially not very useful for reaching a superior non-cooperative outcome, may facilitate a cooperative agreement in international climate negotiations. It is this claim, which we consider here.

Considerable efforts have been made to reach international cooperation in climate summits, with scant success. One of the main reasons for the break-down of efficient bargaining is asymmetric information. For instance, there is imperfect and incomplete information about the impact of abatement efforts on national growth and on the change in the distribution of income. Political decision-makers may also lack information about the political cost and benefit of possible climate agreements for their counterparts in climate negotiations. For instance, a politician may face high or low political cost of agreeing on emission reductions at home, depending on who are the supporters of this politician inside the government coalition, or what is the electoral environment in which this politician pursues his or her career, and this own cost or benefit is typically the private information of each politician who participates in climate negotiations. ${ }^{2}$

\footnotetext{
${ }^{1}$ See, e.g., Lund (1994), Elofsson (2007).

${ }^{2}$ Information issues play an important role in non-cooperative theory on abatement.
} 
We identify a reason why pre-commitment to unilateral abatement is likely to reduce the probability for reaching a cooperative agreement in such a framework. We describe negotiations by a one-sided take-it-or-leave-it offer that is made by the uninformed party. Take-it-or-leave-it offers abstract from many aspects of the complex process of climate negotiations. However, the reason identified here has a strong intuition and can be expected to be robust also in many other, more elaborate bargaining frameworks. ${ }^{3}$

Our work is perhaps closest to the work by Harstad (2007), as we also consider bargaining success in the context of incomplete information. Whereas Harstad (2007) concentrates on the potentially counterproductive role of side-payments, we consider the role of pre-commitment to high abatement levels for the likelihood of a cooperative outcome. We also analyze one-sided commitment in a context without side-payments and see whether this makes side-payments more or less beneficial. As the forces that make side-payments potentially dysfunctional in Harstad's framework are absent in our approach, it may not be surprising that side-payments are beneficial in our framework. Also related to our research question is the work on the role of threat points for cooperative outcomes. This work includes Buchholz and Konrad (1994), who consider the role of commitment on technology choices prior to cooperative Nash bargaining, and Beccherle and Tirole (2011), who analyze investment in $\mathrm{R} \& \mathrm{D}$ in the context of abatement technologies.

On the more general level, our analysis is related to the large literature on the formation and stability of international environmental cooperative agreements. The seminal paper by Carraro and Siniscalco (1993) highlight the incentives to free-ride for single countries on the collective agreements of other countries in the context of complete information. This sceptical view is corroborated by the theory of coalition formation and coalition sta-

Brandt (2004), for instance, considers the role of incomplete information in a repeated noncooperative set-up, in which players can learn about each other's costs by their actions.

${ }^{3}$ There are many bargaining protocols that may be relevant and typically none of them can account fully for the complexity of climate negotiations, which have been described clearly by Barrett (1998). 
bility more generally (Ray and Vohra 2001). ${ }^{4}$ The stability problem and the problem of enforcement are most serious in an international context.

Our problem is orthogonal to this problem. The coalition formation literature considers perfect and complete information and focuses on the problems of commitment and of enforcement of given agreements. We consider asymmetric information as the problem that may prevent cooperation. For this purpose we remove all other obstacles for coalition formation from the picture. In particular, we consider two countries only - hence, there is no further country that could free-ride on the coalition formation of other countries or could break apart from a given coalition, which is the key issue of coalition stability. Further, we assume that, if countries sign an agreement, it is costlessly enforced, in order to remove this type of problem.

Asymmetric information is well-known to be an important obstacle for efficiency enhancing negotiation outcomes. We ask whether unilateral precommitment makes asymmetric information a larger or smaller obstacle for such efficiency enhancing negotiations. We identify a major reason for why unilateral commitment on an efficient abatement level will not improve the efficiency properties of the bargaining problem and may decrease the probability for reaching an efficient outcome.

In what follows we establish the bargaining framework in section 2. We then solve for the perfect Bayesian equilibrium without and with unilateral abatement commitment in sections 3 and 4 and compare success probabilities in section 5. Section 6 analyses the comparative static properties of the

\footnotetext{
${ }^{4}$ Carraro and Siniscalco (1998) offer an early review. Rubio and Ulph (2007) consider a dynamic model of international agreements. Froyn and Hovi (2007) show that repeated interaction can sustain a collusive outcome. Carraro, Marchiori and Oreffice (2009) consider commitment on minimum coalition size, Thoron, Sol and Willinger (2009) approach the issue of coalition formation from an experimental perspective. Altemeyer-Bartscher, Rübbelke and Sheshinksi (2010) consider a mechanism that links side-payments and Pigouvian taxes. Hannesson (2010) considers the role of size differences. Kolstad (2007) analyse a perfect information framework with ex-ante uncertainty in environmental costs and benefits. Kolstad and Ulph (2011) consider ex-post cost heterogeneity and learning about own costs in this framework. Conconi and Perroni (2002) and Lahiri (2011) focus on issue linkages.
} 
main result, considers the role of international side payments in this context and briefly discusses the limitations of the bargaining approach used in this paper. A brief conclusion is drawn in Section 7 .

\section{The formal framework}

Consider an environmental bargaining problem with two countries $A$ and $B$. Each country makes a contribution to global emissions reduction, denoted $e_{A} \in\{0,1\}$ and $e_{B} \in\{0,1\}$. The high abatement level has a cost. The cost for abating $e_{A}=1$ instead of zero units is $\left(1+c_{A}\right)$ for country $A$, where $c_{A} \in(0,1)$, and the cost of $e_{B}=1$ for country $B$ is $\left(1+c_{B}\right)$ with $c_{B} \in(0,1)$. Each country learns its own cost before any decisions are made, but this information is private and the respective other country knows only that the cost parameter of the other country is a random draw from a given distribution with known cumulative distribution function $F(c)$. Throughout we assume

$$
\frac{\partial\left[F(c) / F^{\prime}(c)\right]}{\partial c} \geq 0
$$

The ratio $F(c) / F^{\prime}(c)$ is the inverse hazard rate. The assumption (1) of a non-decreasing inverse hazard rate holds for many commonly considered probability distributions and is a standard regularity assumption in contract theory.

Total abatement is $e=e_{A}+e_{B}$, and each country benefits from total abatement in the same way, and by appropriate normalization, the benefit is equal to $e$. We allow for monetary transfers between the two countries, and define $t$ as the amount of money paid by $A$ and received by $B$. Each country's payoff is the sum of the abatement benefits from the total abatement minus own abatement cost minus transfer paid (plus transfer received). These payoffs can be written, after simplification, as

$$
\pi_{A}=e_{B}-c_{A} e_{A}-t \quad \text { and } \quad \pi_{B}=e_{A}-c_{B} e_{B}+t .
$$

We consider the following two variants of abatement games. One of the games has unilateral pre-commitment by $A$ to high abatement efforts $e_{A}=1$, 
the other game has no such pre-commitment.

More precisely, the pre-commitment game is as follows. In stage 0, country $A$ unilaterally pre-commits to $e_{A}=1$, irrespective of the further interaction. This is not a choice, but part of the rules characterizing this game. Then both countries learn their own abatement costs. In stage 1, country $A$ makes a take-it-or-leave-it offer to country $B .^{5}$ The offer specifies a payment $t$ from $A$ to $B$ in exchange for $B$ 's agreement to provide $e_{B}=1$. In stage 2 country $B$ decides about the offer. If $B$ refuses the offer, then $B$ noncooperatively chooses the abatement effort that maximizes its own payoff. If $B$ accepts the offer, then $B$ receives $t$ and chooses $e_{B}=1$. In both cases country $A$ implements $e_{A}=1$ as it has made this commitment.

The no-commitment game has no abatement commitment taken in stage 0 . Both countries privately learn about their own abatement costs. In stage 1, country $A$ makes a take-it-or-leave-it offer to country $B$. Country $A$ offers to pay an amount $t$ (which can be negative) if, in exchange, both countries abate one unit of emissions. In stage 2 country $B$ decides about whether to accept this offer. If country $B$ accepts the offer, then $e_{A}=e_{B}=1$, and the payment is made. If country $B$ refuses the offer, then each country noncooperatively chooses the abatement effort that maximizes its own payoff.

We solve for the equilibrium for each of the two games and then compare the equilibrium probability of reaching an agreement.

\section{Equilibrium in the pre-commitment game}

Suppose country $A$ has pre-committed to $e_{A}=1$ and has an own abatement cost of $1+c_{A}$. Suppose the offer to country $B$ consists of an amount $t$ that is paid to $B$ in case $B$ accepts the offer and chooses $e_{B}=1$. Solving backwards, if $B$ rejects the offer, then country $B$ non-cooperatively pursues its own interest. Country $B$ chooses $e_{B}=0$ in this case. The resulting

\footnotetext{
${ }^{5}$ Allocating the offer-making right to $B$ is a different modeling choice. Then, however, our format of pre-commitment is no longer appropriate, because it turns the problem essentially into a problem of complete information for player $B$.
} 
payoffs are $\pi_{A}=-c_{A}$ for country $A$, and $\pi_{B}=1$ for country $B$. If country $B$ accepts the offer, the payoff for country $A$ is $\pi_{A}=1-c_{A}-t$, and $\pi_{B}=1-c_{B}+t$ for country $B$. Accordingly, country $B$ accepts the offer if

$$
t \geq c_{B}
$$

As the true value of $c_{B}$ is unknown to country $A$, for a given $t$, the expected payoff of country $A$ from an offer $t$ is $\pi_{A}(t)=F(t)(1-t)-c_{A}$. In equilibrium, country $A$ chooses the $t$ that maximizes this expected payoff. The first-order condition of this problem is

$$
t=1-\frac{F(t)}{F^{\prime}(t)}
$$

Proposition 1 The pre-commitment game has a unique perfect Bayesian equilibrium which is characterized by an offer $t=t_{P} \in(0,1)$ that is the unique solution to (4).

Proof. For any given $t$, country $B$ 's belief about country $A$ 's cost does not matter for $B$ 's decision whether to accept the offer or not. This decision is governed only by (3). Accordingly $A$ 's choice of $t$ is governed by (4) and it remains to be shown that (4) has a unique solution as an intersection of the functions on the left-hand side and the right-hand side of (4). Consider the two sides of (4) as functions of $t$ and search for an intersection. The lefthand side of (4) is the identity function $t=t$; graphically, it is the $45^{\circ}$-line. The right-hand side is also a function of $t$ that is defined on $t \in[0,1]$, takes the value 1 for $t=0$, is non-increasing in $t$ by (1) and takes a value less than 1 for $t>1$. Accordingly, the graph of the function $1-\left(F(t) / F^{\prime}(t)\right)$ must intersect the $45^{\circ}$-line once and only once in the interval $t \in(0,1)$.

We denote the solution to (4) as $t_{P}$. Implicitly, this solution describes the probability for which cooperation is achieved in the equilibrium as $F\left(t_{P}\right)$ 


\section{Equilibrium in the no-commitment game}

We now solve the game without pre-commitment for the perfect Bayesian equilibrium. If $B$ rejects the offer made by country $A$, the non-cooperative equilibrium effort choices are $e_{A}=e_{B}=0$, with payoffs $\pi_{A}=\pi_{B}=0$. If $B$ accepts the offer made by country $A$, then abatement levels $e_{B}=e_{A}=1$ are implemented and the payoffs of $A$ and $B$ are $\pi_{A}=2-\left(1+c_{A}\right)-t=1-c_{A}-t$ and $\pi_{B}=1-c_{B}+t$, respectively. This shows that country $B$ accepts $A$ 's offer if $t \geq c_{B}-1$. For a given $t$, the ex-ante probability that $B$ accepts this offer is the probability that $c_{B} \leq 1+t$, which is $F(1+t)$. The expected payoff of country $A$ as a function of $t$ and the country's own true abatement cost $c_{A}$ amounts to

$$
\pi_{A}(t)=F(1+t)\left(1-c_{A}-t\right)
$$

We find:

Proposition 2 The no-commitment game has a unique perfect Bayesian equilibrium which is characterized by an offer $t_{N} \in(-1,0]$.

Proof. A transfer offer $t$ that maximizes (5) must be from the interval $(-1,0]$ for the following reason: First, $\pi_{A}(t)=0$ for $t \leq-1$, because $F(1+$ $t)=0$ for $t \leq-1$, and

$$
\frac{\partial \pi_{A}(t)}{\partial t}=F^{\prime}(1+t)\left(1-c_{A}-t\right)-F(1+t)
$$

is strictly positive at $t=-1$. This rules out a maximum for $t \leq-1$. Second, as $F^{\prime}(1+t)=0$ for $t>0, \frac{\partial \pi_{A}(t)}{\partial t}=-F(1+t)=-1<0$ for all $t>0$. This rules out a maximum for $t>0$.

The value of $t$ that globally maximizes $\pi_{A}(t)$ is either an interior maximum for $t \in(-1,0)$, or a corner solution with $t=0$. An interior solution is characterized by $\frac{\partial \pi_{A}(t)}{\partial t}=0$, which, by (6) can be written as

$$
t=\left(1-c_{A}\right)-\frac{F(1+t)}{F^{\prime}(1+t)}
$$


The two sides of (7) are functions of $t$. The left-hand side in (7) is the identity function, or graphically, it is the $45^{\circ}$-line in the third quadrant. It has a slope of +1 . The right-hand side takes the value $\left(1-c_{A}\right) \geq 0$ for $t=-1$, as $F(0)=0$. Moreover, the right-hand side in (7) is weakly decreasing in $t$ for $t \in(-1,0)$ by the assumption (1). Accordingly, the graph of the function $\left(1-c_{A}\right)-\frac{F(1+t)}{F^{\prime}(1+t)}$ intersects the $45^{\circ}$-line in the range $t \in(-1,0)$ at most once. If such an intersection occurs, this intersection determines the unique equilibrium offer. If, instead, $\lim _{t \rightarrow 0}\left\{\left(1-c_{A}\right)-\frac{F(1+t)}{F^{\prime}(1+t)}\right\}>0$, then this implies $\lim _{t \rightarrow 0}\left(\frac{\partial \pi_{A}(t)}{\partial t}\right)>0$, and in turn, the unique $t$ that maximizes (5) is $t=0$.

The payoff-maximizing transfer offer $t_{N}$ is non-positive, and may therefore also be called an asking price. However, we stick to the terminology and denote $t$ as the transfer from $A$ to $B$, even if this transfer is negative. The transfer is a function $t_{N}\left(c_{A}\right)$, and determines the probability for the emergence of a cooperative outcome as $F\left(1+t_{N}\left(c_{A}\right)\right)$ in the equilibrium.

\section{Comparing success probabilities}

We now compare the likelihood for cooperation to take place with and without pre-commitment. Our main result is summarized in:

Proposition 3 For all possible $c_{A}$, the probability that $A$ and $B$ agree on a cooperative outcome is higher in the regime without a pre-commitment.

Proof. The proposition holds if $F\left(1+t_{N}\left(c_{A}\right)\right)>F\left(t_{P}\right)$. This comparison turns into the question of whether $1+t_{N}>t_{P}$. The transfer offer $t_{P}$ is always described by (4). For $t_{N}$ we need to distinguish between an interior solution and a corner solution with $t_{N}=0$.

For an interior solution $1+t_{N}>t_{P}$ is equivalent to $1+\left(1-c_{A}\right)-$ $\frac{F\left(1+t_{N}\right)}{F^{\prime}\left(1+t_{N}\right)}>1-\frac{F\left(t_{P}\right)}{F^{\prime}\left(t_{P}\right)}$. The two sides of this inequality are of the same structure which may be described more generally as a function $x=m-\frac{F(x)}{F^{\prime}(x)}$, which implicitly defines a function $x(m)$ for a certain range $m \in M$. For this function, 


$$
\frac{d x}{d m}=\frac{1}{\left(1+\frac{\partial \frac{F(x)}{F^{\prime}(x)}}{\partial x}\right)}>0 .
$$

The inequality in (8) holds if $x(m)$ is an increasing function in $m$ on the whole range, which holds for $F(c)$ by the standard regularity assumption we imposed on $F(c)$. As $\left(2-c_{A}\right)>1$ for all $c_{A} \in(0,1)$ this implies $1+t_{N}\left(c_{A}\right)>$ $t_{P}$.

For a corner solution with $t_{N}=0$ the condition $1+t_{N}>t_{P}$ is always fulfilled as $t_{P}<1$.

The proposition shows that a pre-commitment to high abatement contributions reduces the likelihood of reaching an efficient outcome. The basic intuition for this result is as follows. In the case with pre-commitment, $A$ and $B$ negotiate only about the value added that emerges from $B$ 's possible abatement. Without pre-commitment, $A$ 's stakes of reaching an agreement are much higher. This makes failure more painful for player $A$ in the case without pre-commitment and makes player $A$ choose a less aggressive strategy. In case of an agreement, $A$ can "sell" also $B$ 's benefit of $A$ 's own abatement to $B$. $A$ can charge the full rent that is generated by this transaction. However, $A$ can obtain this benefit only if $B$ accepts $A$ 's offer. Hence, $A$ is more cautious and reduces the risk of a negotiation failure.

\section{Extensions and Robustness}

In this section we consider the comparative static properties of the result, the role of side payments, and briefly discuss the robustness of the result in a more sophisticated bargaining context.

Comparative statics We can also verify the following comparative static property

Proposition 4 The transfer $t_{P}$ offered and the probability $F\left(t_{P}\right)$ of successful negotiations in the pre-commitment equilibrium are independent of 
$c_{A}$. The transfer $t_{N}$ offered and the probability of successful negotiations in the no-commitment equilibrium are higher the lower the abatement cost $c_{A}$.

Proof. The first part of the proposition is obvious from the fact that $t_{P}$ is uniquely determined by (4) and independent of $c_{A}$. The second part of the proof follows from the proof of Proposition 3: $x(m)$ is an increasing function in $m$ and $m$ is a decreasing function in $c_{A}$.

Intuitively, with pre-commitment, $A$ 's decision for $e_{A}=1$ has already been made, and the cost does not influence the further decisions. Without pre-commitment, the additional value of successful bargaining for $A$ is higher if country $A$ 's own cost of abatement is lower.

No side-payments In the analysis so far, we have allowed country $A$ to make transfers. As has been shown in Harstad (2007), such side-payments need not improve the efficiency of bargaining under incomplete information. It is therefore interesting to ask whether a unilateral pre-commitment may become superior to bargaining if side-payments are not allowed.

Consider first the case with pre-commitment. If $A$ has chosen $e_{A}=1$ and if the only feasible take-it-or-leave-it offer has $t=0$, then the probability of a cooperation failure is 1 : $B$ will reject this offer with probability 1 , because the own benefit of abatement is smaller than $B$ 's own cost. The outcome is more favorable in the case without pre-commitment. In this case, $B$ will always accept an offer if the transfer is exogenously fixed at $t=0$ as country $B$ 's payoff increases from $\pi_{B}=0$ to $\pi_{B}=1-c_{B}>0$ if it accepts the offer. We formulate this as

Proposition 5 Without side-payments $\left(t_{P}=t_{N}=0\right)$, pre-commitment leads to bargaining failure with probability 1 . If no pre-commitment is made, the probability of cooperation is equal to 1.

Intuitively, if symmetric abatement choices are efficient and yield a Pareto improvement, then cooperation is possible even if $t$ is fixed to zero. Unilateral pre-commitment to high abatement then introduces a major asymmetry 
in payoffs into the bargaining problem. Without side-payments, the move from the non-cooperative outcome (after unilateral abatement) can never be a Pareto improvement. Hence, whether transfers should be part of the bargaining framework will generally hinge on whether the efficient outcome is an element in the set of Pareto improvements or not.

More general bargaining frameworks As discussed in the introduction, take-it-or-leave-it offers provide a stark framework for the study of asymmetric bargaining. They reduce complexity and highlight an important aspect of pre-commitment choices. Pre-commitment to large unilateral abatement takes away some of the possible gains from bargaining, reducing the total benefits of reaching a negotiation outcome. As higher benefits from cooperation should make players generally more interested in reaching a cooperative outcome, we expect that pre-commitments have qualitatively similar effects for bargaining failure in other setups of bargaining with incomplete information. It would clearly be desirable to investigate these setups in more detail, but we leave this to future research.

\section{Conclusions}

Pre-commitment to unilateral abatement efforts prior to climate summits has been advocated as a means to facilitate cooperative agreements. We show that such pre-commitment reduces the potential gains from cooperation, and that this may reduce the likelihood for an efficient agreement to be reached in a context with asymmetric information.

\section{References}

[1] Altemayer-Bartscher, Martin, Dirk T.G. Rübbelke, and Eytan Sheshinski, 2010, Environmental protection and the private provision of international public goods, Economica, 77(308), 775-784. 
[2] Barrett, Scott, 1998, On the theory and diplomacy of environmental treaty-making, Environmental \& Resource Economics, 11(3-4), 317333.

[3] Beccherle, Julien and Jean Tirole, 2011, Regional initiatives and the cost of delaying binding climate change agreements, Journal of Public Economics, 95(11-12), 1339-1348.

[4] Brandt, Urs Steiner, 2004, Unilateral actions, the case of international environmental problems, Resource and Energy Economics, 26(4), 373391.

[5] Buchholz, Wolfgang, and Kai A. Konrad, 1994, Global environmental problems and the strategic choice of technology, Journal of Economics, 60(3), 299-321.

[6] Carraro, Carlo, Carmen Marchiori and Sonia Oreffice, 2009, Endogenous minimum participation in international environmental treaties, Environmental \& Resource Economics, 42(3), 411-425.

[7] Carraro, Carlo, and Domenico Siniscalco, 1993, Strategies for the international protection of the environment, Journal of Public Economics, $52,309-328$.

[8] Carraro, Carlo, and Domenico Siniscalco, 1998, International environmental agreements: incentives and political economy, European Economic Review, ,42(3-5), 561-572.

[9] Conconi, Paola, and Carlo Perroni, 2002, Issue linkage and issue tie-in in multilateral negotiations, Journal of International Economics, 57(2), 423-447.

[10] Elofsson, K., 2007, Cost uncertainty and unilateral abatement, Environmenal \&3 Resource Economics, 36(2), 143-162.

[11] Froyn, Camilla Bretteville, and Jon Hovi, 2007, A climate agreement with full participation, Economics Letters, 99(2), 317-319. 
[12] Hannesson, Rognvaldur, 2010, The coalition of the willing: effect of country diversity in an environmental treaty game, Review of International Organizations, 5(4), 461-474.

[13] Harstad, B., 2007, Harmonization and side payments in political cooperation, American Economic Review, 97(3), 871-889.

[14] Hoel, Michael, 1991, Global environmental problems - the effects of unilateral actions taken by one country, Journal of Environmental Economics and Management, 20(1), 55-70.

[15] Kolstad, Charles D., 2007, Systematic uncertainty in self-enforcing international environmental agreements, Journal of Environmental Economics and Management, 53(1), 68-79.

[16] Kolstad, Charles D., and Alistair Ulph, 2011, Uncertainty, learning and heterogeneity in international environmental agreements, Environmental $\& 3$ Resource Economics, 50(3), 389-403.

[17] Lahiri, Bidisha, 2011, The welfare synergy of bundling international environmental agreements with international trade treaties, Review of International Economics, 19(5), 909-921.

[18] Lund, Diderik, 1994, Can a small nation gain from a domestic carbon tax - the case with research and development externalities, Scandinavian Journal of Economics, 96(3), 365-379.

[19] Ray, Debraj, and Rajiv Vohra, 2001, Coalitional power and public goods, Journal of Political Economy, 109(6), 1355-1384.

[20] Rubio, Santiago J., and Alistair Ulph, 2007, An infinite-horizon model of dynamic membership of international environmental agreements, Journal of Environmental Economics and Management, 54(3), 296-310.

[21] Thoron, Sylvie, Emmanuel Sol and Marc Willinger, 2009, Do binding agreements solve the social dilemma? Journal of Public Economics, 93(11-12), 1271-1282. 